\title{
A IMPORTÂNCIA DA INTEGRAÇÃO ENERGÉTICA NA AGENDA DAS FORÇAS ARMADAS DA UNASUL
}

\section{Miguel Patrice Philippe Dhenin ${ }^{1}$}

\begin{abstract}
Resumo: Este artigo tem como objetivo discutir a questão da segurança energética no âmbito da União Sul-Americana das Nações (UNASUL). Pretendemos evidenciar os vínculos existentes entre as questões de segurança energética, a especificidade da zona e as ramificações com as questões de defesa para os membros da UNASUL. As construções teóricas oferecidas por Buzan e Wæver compõem o escopo teórico do artigo. Medidas efetivas para afastar da sociedade o risco da falta de energia ou para diminuir a instabilidade de acesso às fontes energéticas exigem a identificação e a aplicação de ações de modo a permitir que o Estado tenha um planejamento de cunho estratégico. A Declaração de Margarita foi um marco importante para realizar esse objetivo entre os países da UNASUL, pois criou um Conselho Energético que se encarregou de apresentar uma estratégia energética, um plano de ação e um tratado para a integração de energia na região. Os planejadores buscaram nos estudos estratégicos conhecimentos para diminuir a vulnerabilidade e a dependência energética de seus países. A escassez dos investimentos, a falta de interligação da malha energética sul-americana e os desequilíbrios na quantidade de recursos energéticos entre os países representam alguns vetores de tensões entre os diferentes países da comunidade. Logo, o papel das Forças Armadas das nações da UNASUL nesse contexto aparece como determinante para garantir a segurança e a estabilidade da região.
\end{abstract}

Palavras-chave: UNASUL, integração energética, segurança energética.

Resumen: Este artículo pretende discutir el tema de la seguridad energética de la Unión de Naciones Suramericanas (UNASUR). Tenemos la intención de destacar los vínculos entre las cuestiones de seguridad energética, la especificidad de la zona y las ramificaciones de las cuestiones de defensa para los miembros de UNASUR. Los constructos teóricos ofrecidos por Buzan y Waever conforman el marco teórico del artículo. Medidas eficaces para evitar el riesgo de la falta de la sociedad e la energía o para reducir la inestabilidad de acceso a las fuentes de energía requieren la identificación e implementación de acciones para que el Estado tenga un plan de carácter estratégico. La Declaración de Margarita fue un hito importante para lograr este objetivo entre los países de UNASUR, creó un Consejo de Energía que se comprometió a proporcionar una estrategia energética, un plan de acción yun tratado para la integración energética en la región. Planificadores buscó el conocimiento en los estudios estratégicos para reducir la dependencia energética y la vulnerabilidad de sus países. La escasez de inversiones, la falta de interconexión de redes eléctricas de América del Sur y los desequilibrios en la cantidad de los recursos energéticos entre los países representan un vector de las tensiones entre los diferentes países de la Commonwealth. Así, el papel de las fuerzas armadas de las naciones de UNASUR ha sido decisiva en este contexto, para garantizar la seguridad y la estabilidad en la región.

Palabras-clave: UNASUR, integración energética, seguridad energética.

Abstract: This article aims to discuss the issue of energy security within the Union of South American Nations (UNASUR). We intend to highlight the linkages between energy security issues, the specificity of the area and the ramifications with defense issues for members of UNASUR. The theoretical constructs offered by Buzan and Wæver make up the theoretical scope of the article. Effective measures to avert the risk of society's lack of energy or to reduce the instability of access to energy sources require the identification and implementation of actions to allow the state to have a plan of strategic nature. The Declaration of Margarita was an important milestone to achieve this goal among the countries of UNASUR, it created an Energy Council which undertook to provide an energy strategy, an action plan and a treaty for the energy integration in the region. Planners sought knowledge in strategic studies to reduce energy dependence and vulnerability of their countries. The scarcity of investment, lack of power grid interconnection of South American and imbalances in the amount of energy resources between countries represent some vector of tensions between the different Commonwealth countries. Thus, the role of the armed forces of the nations of UNASUR has been decisive in this context to ensure security and stability in the region.

Key-words: UNASUR, energy integration, energy security.

${ }^{1} \mathrm{O}$ autor desse artigo possui mestrado em Estudos Estratégicos da Segurança e da Defesa da Universidade Federal Fluminense. É formado em Ciência Política e Direito na Université de Versailles (França). 


\section{APRESENTAÇÃO}

A integração energética do continente latino-americano aparece, à primeira vista, bastante evidente: os países sul-americanos são complementares em termos de recursos naturais e os governos favorecem a criação de instituições comuns. Muitos projetos ambiciosos foram concretizados (como por exemplo, a usina hidrelétrica binacional Itaipu) e a cooperação regional entre os parceiros continua sendo uma preocupação importante entre os Estados. Nos últimos vinte anos, a energia tem perdido a sua importância para medir a força econômica de uma nação. Porém, o seu impacto manteve toda a sua relevância geopolítica. Este componente chave da matriz energética sul-americana reflete a importância dos hidrocarbonetos na pauta das discussões internacionais. O petróleo e o gás representam cerca de $60 \%$ do consumo global de energia e metade do combustível utilizado para a mobilidade física das pessoas e dos bens, elemento essencial da globalização econômica.

\section{METODOLOGIA}

Para entender as questões de integração na América do Sul, começaremos usando o conceito de segurança energética desenvolvido pela Escola de Copenhague sobre estudos de segurança" (Copenhagen School of security studies) As teorias oferecidas por essa corrente são relevantes para compreender a relação entre energia e integração regional, particularmente na América do Sul. Tendo definido este conceito, faremos um inventário do setor energético regional, a partir de dois tipos de hidrocarbonetos vetores de tensões: o petróleo e o gás. Em seguida, analisaremos diversos cenários que revelam a dificuldade de estabelecer uma estratégia para a integração energética na União das Nações sul-americanas. Uma série de esforços tem sido realizada, incluindo o estabelecimento de cúpulas internacionais, marco de uma reconciliação com a visão da diplomacia dos diferentes parceiros regionais. Por fim, concluiremos este trabalho, salientando a importância estratégica da criação de um Conselho sul-americano de Defesa, cujo objetivo principal é limitar ou impedir os conflitos regionais (problemas de fronteiras ou instabilidade política, por exemplo) e promover uma diplomacia latino-americana independente capaz de resolver qualquer crise política regional. 


\section{SEGURANÇA ENERGÉTICA: CONCEITO E DEFINIÇÕES}

A partir das construções teóricas oferecidas pelos professores Barry Buzan e Ole Waever - especialistas no campo da segurança internacional - a segurança energética pode ser definida como um conceito elástico. ${ }^{2}$ Estabelecendo uma conexão entre as questões de segurança propriamente dita hard security - proteção do território, dos recursos naturais, o suprimento de combustíveis vitais - com questões de "segurança ampliada" ou soft security o que englobaria questões econômicas e de desenvolvimento sustentável, implicando inclusive, em questões de proteção ambiental mais genericamente. Isso propiciaria um engajamento de mais países com mais interesses envolvidos, traduzindo-se em boas perspectivas de cooperação nos âmbitos sul-americano e europeu. Para esses autores, "segurança é sobrevivência, ou seja, somente se pode falar em segurança quando um assunto é apresentado como sendo uma ameaça real a algum objeto (tradicionalmente, mas não necessariamente o Estado, incorporando o governo, o território e sociedade). E, utilizando-se de um conceito defendido por Waever, afirmam que a especial natureza da ameaça justifica o uso de medidas extraordinárias e/ou urgentes a fim de lidar com ela. ${ }^{\text {” }}$

Sob essa ótica realista das Relações Internacionais, os países que dependem de recursos energéticos importados têm dois objetivos principais: primeiro, adotar políticas destinadas a assegurar o acesso ao suprimento externo adicional que é essencial para suas necessidades nacionais (pode procurar relações bilaterais com os principais produtores; pode criar um sistema de fornecedores preferenciais ou pode participar de esforços internacionais ainda mais amplos, como a Agência Internacional de Energia (AIE) e a Conferência de Cooperação Econômica Internacional (CCEI); segundo, reduzir a necessidade de acesso a suprimentos externos (um governo pode programar políticas de conservação, oferecer incentivos para o desenvolvimento de alternativas energéticas, incentivar as pesquisas, etc). Essas são medidas essencialmente internas que um governo pode tomar para reduzir a demanda e estimular a produção. O sucesso dessas políticas será determinado pela oportunidade das medidas, pela decisão com que forem adotadas, pelas políticas econômicas vigentes e pela disponibilidade de recursos energéticos naturais no país. No caso do Brasil, esses recursos são muito importantes e diversificados, como mostra a sua matriz energética.

\footnotetext{
2 BUZAN, Barry; WAEVER, Ole. Regions and Power: The Structure of International Security, Cambridge, Cambridge University Press, 2004

3 RUDZIT, G. O debate teórico em segurança internacional. Mudanças frente ao terrorismo? Revista Civitas de Ciências Sociais, vol. 5, número 2, julho - dezembro de 2005 p. 307
} 


\section{A SEgURANÇA ENERGÉticA NA AMÉRICA DO SUL: O PROBLEMA DO PETRÓLEO E DO GÁS NATURAL}

O petróleo e o gás representam o foco principal dos projetos de cooperação energética do continente latino-americano. Esta região do mundo aparece de fato favorável à integração dos mercados de energia, principalmente pela quantidade de recursos disponíveis, mas também pelos desequilíbrios existentes entre os diferentes países. Podemos levar em consideração dois estudos de casos para fortalecer nossa argumentação, mostrando a complexidade das questões energéticas na região. Em primeiro lugar, faremos uma pequena análise do problema do petróleo na América do Sul, a partir do exemplo das complexas relações entre a Venezuela e dos seus vizinhos, para ilustrar as dificuldades enfrentadas no desenvolvimento de um projeto de integração. Em seguida, observaremos a complexidade das questões relativas ao gás na América do Sul, esboçada a partir da questão boliviana.

\section{O problema do petróleo na América do Sul: a questão de Chávez para o equilíbrio da região}

A Venezuela tem uma das maiores reservas de hidrocarbonetos do mundo, colocando o país no quinto lugar em termos de reservas comprovadas. Além disso, isto representa cerca de metade das reservas de petróleo na região. A empresa pública PDVSA tem uma capacidade de produção de cerca de 4 milhões de barris por dia (600.000 $\mathrm{m}^{3}$ ), enquanto a produção de gás é superior a 3 milhões de barris por dia (500.00o $\mathrm{m}^{3}$ ). O total das reservas comprovadas é de 78 bilhões de barris de petróleo e 148 trilhões de metros cúbicos de gás natural.4 As tensões políticas após o golpe fracassado contra Hugo Chávez reforçaram a importância do petróleo como instrumento diplomático do governo. Com efeito, apesar de uma aparente hostilidade em relação aos Estados Unidos, a Venezuela continua sendo um importante parceiro econômico para os norte-americanos no quesito energético. O relacionamento com o Brasil, líder político regional, aparece positivo. Porém, precisamos ressaltar as tensões existentes entre a Venezuela e os demais países do continente, tendo em consideração a ambivalência das declarações feitas por Hugo Chávez, principalmente com o apoio às Forças Armadas Revolucionárias da Colômbia em diversos discursos. No entanto, pela sua tradição, os fatos comprovaram que o Brasil escolheu o canal diplomático, para fortalecer a estabilidade da região, favorecer o comércio na fronteira, acelerar a integração e, sobretudo, priorizar o diálogo como primeira solução diplomática na

\footnotetext{
4 MINISTERIO DE PLANIFICACIÓN Y DESARROLLO DE LA REPÚBLICA BOLIVARIANA DE VENEZUELA. Dados sobre o setor do petróleo disponíveis em < http://www.mpd.gov.ve>
} 
resolução dos conflitos. A segunda estratégia é muito mais recente, porém, ela está sendo ainda avaliada. Ela se compõe novamente de uma série de acordos comerciais e promove as interconexões. Contudo, apresenta a peculiaridade de tentar partilhar os recursos energéticos e de estabelecer ligações com projetos comuns de produção. Esta postura é incentivada pelo governo venezuelano e o ator principal desse esforço, a empresa pública PDVSA. Ela está sendo implementada a partir dos projetos comuns ou de uma empresa mista entre PDVSA e um parceiro local, geralmente uma empresa pública. Mas, em contrapartida, esse parceiro pode participar das atividades petrolíferas venezuelanas. Se existem pagamentos em espécie, também é comum a utilização de outros meios como, por exemplo, o pagamento em produtos locais exportados para a Venezuela. Em muitos casos, existe um claro desequilíbrio entre os custos cobertos pelas duas partes e a Venezuela dá mais do que recebe.

\section{A segurança energética na América do Sul: a questão do gás boliviano}

Os litígios relativos ao setor do gás exemplificam as diferenças entre as declarações feitas durante as reuniões internacionais e as relações concretas entre os países. Desde que o presidente da Bolívia, Evo Morales, havia adotado medidas para controlar a extração e venda de petróleo em maio de 2006, vários conflitos surgiram com o gigante brasileiro. Para este último, o gás boliviano é essencial para a sua energia e representa uma contribuição chave da sua matriz energética. ${ }^{5}$ Após muitos meses de discussões, as negociações sobre o preço do gás foram realizadas, seguido de negociações para a transferência das refinarias da Petrobras na Bolívia sob controle da estatal boliviana YPFB. No entanto, a persistência das tensões regionais e a falta de homogeneidade dos países da América do Sul tornam complicada a cooperação energética. Além disso, determinadas questões geopolíticas em torno de projetos de integração alimentam as tensões. O subcontinente precisa desenvolver uma estratégia de longo prazo para fortalecer os acordos bilaterais já firmados, nesse caso entre o Brasil e a Bolívia. A primeira opção não permite a realização de projetos conjuntos desse tipo, e por conseqüência, os países não dividem os poços de hidrocarbonetos. Os mesmos, explorados diretamente ou sujeitos às concessões, permanecem submetido às regulamentações comerciais muito rígidas. Um bom exemplo é o papel do Brasil e da Petrobras, pois as polêmicas em torno dessa empresa não aconteceram somente na Bolívia, mas foram também repetidas no Equador, no Peru e na Argentina.

\footnotetext{
5 PACHECO MIRANDA, Carlos. Importancia Estratégica del gas boliviano. IN: Perspectivas Internacionales, LaPaz, $\mathrm{n}^{\circ} 5$, abril de 2005. Disponível em :

<http://www.fes.cl/documentos/polint/PerspectivasInternacionales/5-Miranda.pdf >
} 


\section{As conseqüiências da Declaração de Margarita para a União Sul-Americana das Nações: uma série de acordos para promover a integração energética.}

A heterogeneidade da União Sul-Americana das Nações exigiu dos diferentes atores envolvidos a necessidade de encontrar um ponto de vista comum em favor da integração energética. Os avanços diplomáticos realizados nos últimos anos, incluindo uma reconciliação entre as nações, fortaleceram o esforço comum para uma integração efetiva do continente, através de reuniões, cúpulas e outros tratados assinados nos últimos anos. Por exemplo, podemos citar a Convenção de Lima de 1973, que deu origem à Organização Latino-Americana de Energia (Organización Latinoamérica de Energía ou OLADE), e inúmeros compromissos bilaterais assinados após os choques petroleiros de 1970 e 1973. Mais recentemente, a energia foi o foco das negociações, no âmbito da Comunidade Andina de Nações (CAN) com a Aliança Energética dos Andes, assinada em 2004. Houve também um esforço realizado do MERCOSUL com a Declaração de Assunção, em 2005.

Neste contexto, nos dias 16 e 17 de abril de 2007, uma reunião de chefes de Estados de países sul-americanos foi realizada em Isla Margarita (Venezuela). Os principais chefes de Estados presentes foram: o presidente Hugo Chávez (Venezuela), o presidente Nestor Kirchner (Argentina), o presidente brasileiro Luis Inácio Lula da Silva; o presidente da República da Bolívia Evo Morales, o presidente Nicanor Duarte do Paraguai, o presidente Rafael Correa (Equador), o presidente Álvaro Uribe (Colômbia); a presidente do Chile Michelle Bachelet, o vice-presidente do Uruguai, Rodolfo Nin Novoa, o primeiro-ministro da Guiana, Sam Hinds, e o primeiro-ministro adjunto do Suriname Gregory Rusland.

$\mathrm{Na}$ cimeira, os objetivos foram claramente apresentados para que o sucesso de todos os países participantes fosse efetivo. O planejamento das políticas públicas foi também apresentado. Assim, de acordo com a Declaração final, a integração energética "deve ser usada como um instrumento importante para promover o desenvolvimento econômico e social e a erradicação da pobreza", ela também "envolve principalmente o Estado, a sociedade e as empresas relacionadas com o setor da energia, sem esquecer as tradicionais chamadas de cooperação técnica." Este tipo de compromissos gerais foi dito repetidamente nas declarações presidenciais nos últimos anos para acentuar o comprometimento de cada país com o projeto. As decisões mais significativas foram, entre outras, a criação do Conselho Energético da América do Sul (ou Consejo Energético de Suramérica), composto pelos Ministros da Energia dos países envolvidos.

\footnotetext{
${ }^{6}$ Declaração de Margarita, disponível no site do Ministério das Relações Exteriores do Governo Federal: $<$ http://www.itamaraty.gov.br/sala-de-imprensa/notas-a-imprensa/2007/04/18/declaracao-demargarita-construindo-a-integracao >
} 
O Conselho deverá elaborar uma estratégia continental, um plano de ação e uma proposta concreta para estabelecer um Tratado Energético sul-americano. De novo, os presidentes reconheceram a importância da sinergia das ações conjuntas e mencionaram diretamente o plano venezuelano Petroamérica. Precisamos salientar que a Declaração de Margarita não inclui nenhuma medida tangível para promover outro tipo de integração energética, cujos recursos serão partilhados além das interrelações ou a compra e venda de petróleo ou gás.

Os países participantes não conseguiram chegar a um acordo sobre outras questões importantes. Eles não se comprometeram formalmente com a criação de uma organização internacional de países exportadores de gás nem para defender o grande Gasoduto do Sul como um projeto comum, atualmente sob a tutela da Venezuela, do Brasil e da Argentina. Os biocombustíveis têm sido objeto de longas discussões entre as delegações, principalmente porque o Brasil tem defendido até o final aceitar afirmação no contexto da diversidade de fontes de energia (a Bolívia tem manteve um ponto de vista ambivalente sobre essa questão). Não havia nenhum acordo para o lançamento do Banco do Sul, uma proposta que foi o centro das discussões, com a respectiva iniciativa da Venezuela, da Argentina e do Equador. O Brasil rejeitou a proposta. Outros países aceitaram os termos do compromisso, e novas discussões estão em andamento.

Assim, a energia parece desempenhar um papel de catalisador para a integração regional, especialmente pelo fato de a cooperação nesta área atender à demanda energética associada ao crescimento de países sul-americanos. No entanto, é manifesto que a cooperação continua a ser limitada. Parece que a falta de homogeneidade dos países e os conflitos entre eles limitam as possibilidades de cooperação energética, apesar da boa vontade de fachada. Em primeiro lugar, os países da América do Sul são caracterizados pela heterogeneidade de suas economias. Alguns países têm um produto interno bruto7 (PIB) relativamente elevado, como o Brasil e a Venezuela, enquanto outras nações que são essenciais para a cooperação energética regional, principalmente a Bolívia e o Equador, têm um PIB baixo.

Estas diferenças têm implicações sobre a possibilidade de integração energética, para países como possuir diversas habilidades diferentes e objetivos organizacionais. Além disso, enquanto alguns seguem o caminho da nacionalização das suas indústrias de energia, isso não é o caso de todos. A Colômbia e o Peru não seguiram os exemplos da Venezuela e da Bolívia no setor e manterem um setor privado.

\footnotetext{
$7 \mathrm{O}$ produto interno bruto (PIB) representa a soma (em valores monetários) de todos os bens e serviços finais produzidos numa determinada região, durante um período determinado (mês, trimestre, ano, etc). $\mathrm{O}$ PIB é um dos indicadores mais utilizados na macroeconomia com o objetivo de mensurar a atividade econômica de uma região.
} 


\section{INTEGRAÇÃO ENERGÉTICA E ESTUDOS ESTRATÉGICOS: UMA POSSÍVEL ÁREA DE CONFLITO?}

A América Latina é uma região caracterizada por inúmeras tensões que prejudicam a cooperação energética. Assim, o Chile tem dificuldade para obter gás da Bolívia, devido à hostilidade que existe entre os dois países desde a Guerra do Pacífico. Da mesma forma, as tensões entre a Venezuela e a Colômbia não colaboram promover iniciativas conjuntas. Verifica-se assim, de acordo com Frédérique Langue, que "o contexto regional é rico em conflitos, especialmente por causa das reivindicações de fronteiras pendentes. Nos últimos anos, alguns conflitos relacionados com o petróleo ou o gás foram disparados. Trata-se das "guerras do gás" deflagradas com a decisão da Bolívia de aumentar as suas tarifas de exportação e sua recusa em fornecer o Chile. ${ }^{8 ”} \mathrm{~A}$ Argentina, que anteriormente serviu como país tampão, vendia parte do gás boliviano para o Chile, foi forçada, devido à crescente demanda doméstica, a reduzir as suas exportações de gás para o seu vizinho. No entanto, o país é muito dependente da oferta e este se encontra numa posição difícil. Outras tensões foram evidenciadas quando a Bolívia decidiu de maneira unilateral a nacionalização de seus recursos energéticos sem levar em consideração que a empresa brasileira Petrobras investiu cerca de três bilhões de euros no país desde 1997. Este tipo de comportamento não-cooperativo, muitas vezes resultante de tensões pré-existentes, diminui a cooperação dos países sulamericanos e os obrigou muitas vezes a pensar em soluções alternativas. ${ }^{9}$

Assim, o Peru preferiu investir no gás da Indonésia, ou como o Brasil, favorecendo a cooperação energética crescente de países terceiros (os Estados Unidos permanecendo em primeiro lugar).

O recrudescimento do nacionalismo tornou-se uma grande preocupação para todos os atores globais no setor da energia, dos Estados ou das empresas multinacionais. Muitos países produtores de petróleo e de gás tentaram recuperar o controle dos seus recursos naturais, cuja exploração pode ser compartilhada com as companhias internacionais de petróleo e de gás. Esse fenômeno deve permanecer nos próximos anos. Mas o nacionalismo e os investimentos estrangeiros raramente se misturam, especialmente em países produtores que não têm competência técnica e humana própria, o que permitiria em longo prazo a substituição das empresas estrangeiras de petróleo e gás instaladas nos países sul-americanos.

${ }^{8}$ LANGUE, Frédérique. Hugo Chavez et le Vénézuela. Une action politique au pays de Bolivar. Editions L'Harmattan, Paris, 2002

9 EGLER, Cláudio A. G. Energia e Conflitos territoriais na América do Sul: uma visão geoeconômica. Trabalho apresentado no VII Encontro Nacional da ANPEGE, Niterói, Rio de Janeiro. 2007. Disponível em: <http://www.laget.igeo.ufrj.br/egler/pdf/ANPEGE_3.pdf> 


\section{DEFESA E INTEGRAÇÃO ENERGÉTICA: O PAPEL DETERMINANTE DAS FORÇAS ARMADAS DA UNASUL}

De acordo com Alex Sánchez, do Council on Hemisferic Affairs (COHA), a criação do Conselho Sul-americano de Defesa (CSD) é explicada pelo fato de que a Organização dos Estados Americanos (OEA), amplamente dominada pelos Estados Unidos, que têm tradicionalmente mostrado uma tendência às intervenções unilaterais, seria incapaz de administrar as questões de segurança e defesa da região. ${ }^{10}$ Segundo Hector Luis Saint-Pierre, ${ }^{11}$ a relevância do CSD é justamente ligada ao fato de que decisões importantes poderiam ser tomadas não só por considerações pessoais ou interesses alheios, como teria sido o caso em que hoje chamamos de crise andina de 2008. Na verdade, a influência histórica que tiveram os Estados Unidos na OEA ou mesmo os laços especiais existentes com diferentes estados, incluindo a Colômbia, tornou evidentes as dúvidas sobre a neutralidade da administração norte-americana no que diz respeito às questões de segurança na América do Sul. Agora se torna relevante estudar a proposta que oferece o Conselho sul-americano de Defesa e como esta organização pode ser no futuro uma fonte eficiente no esforço conjunto de integração regional. A América Latina parece ser capaz de criar novas alianças regionais em detrimento daquelas já existentes. O CSD seria diferente? De acordo com os 12 países da UNASUL participantes desta iniciativa de defesa, o CSD permitirá estabelecer um fórum de análise e discussão de temas relacionados à defesa e contribuir para a consolidação do continente como zona de paz e de cooperação. Eventualmente, o Conselho também poderá contribuir para a formação de uma identidade sul-americana em matéria de defesa, bem como ser vetor de maior confiança e transparência entre os Estados, a fim de promover uma posição comum de defesa na América Latina e, especialmente, livre da influência americana.

De acordo com Saint-Pierre, o CSD deve ser visto como "uma tentativa de integrar a visão de defesa sub-regional, a fim de discutir as necessidades da defesa comum. Ele iria defender os princípios gerais como a consolidação da democracia e da paz, a não-intervenção nos assuntos internos e o respeito à soberania dos países da subregião, à autodeterminação e à integridade territorial. ${ }^{12 "}$

${ }^{10}$ SÁNCHEZ, Alex, "The South American Defense Council, UNASUR, the Latin American Military and the Region's Political Process", Council on Hemispheric Affairs Primeiro de outubro de 2008, disponível em $<$ http://www.coha.org/2008/10/the-south-american-defense-council-unasur-the-latin-americanmilitaryand-the-regions-political-process/>

${ }^{11}$ ST-PIERRE, Héctor L., "Brasil: Política externa y defensa subregional", apresentação realizada durante o seminário internacional "Límites y desafíos de la agenda de seguridad hemisférica" na cidade de La Paz em 2008, Observatorio de Democracia y Seguridad \& Woodrow Wilson Center for Scholars

${ }^{12}$ ST-PIERRE, Héctor L. Ob. Cit. 


\section{RESULTADOS}

Quando realizamos uma análise das condições para a integração energética na América do Sul, devemos em primeiro lugar salientar os esforços de aproximação realizados nos últimos anos entre as diferentes nações. Na verdade, desde a Declaração de Margarita, os Estados-membros da UNASUL mostraram uma real vontade de cooperar na pauta da integração energética, principalmente em favor de um projeto comum na América Latina. Este projeto é significativo e, em certa medida, reflete características do continente, diversificado, complexo e rico. No entanto, nos parece importante ressaltar o fato de que existe uma série de dificuldades na elaboração da UNASUL. Tomemos por exemplo, as tensões políticas, as crises diplomáticas, as assimetrias regionais que possam de alguma forma impedir a conclusão do projeto de integração energética. Portanto, as diferenças tanto no plano dos recursos como no peso geopolítico dos Estados requerem um aprofundamento dos acordos para que eles possam realmente cumprir os objetivos fixados. É claro que existem grandes diferenças entre os países como o Brasil, primeiro produtor e consumidor de energia na América do Sul, e as demais nações do continente. O gigante brasileiro tem pretensões no mercado mundial e no mercado regional de energia. $\mathrm{O}$ vizinho argentino, por sua vez, encontra-se dependente de uma série de países na sua fronteira para garantir o bom funcionamento da sua matriz energética. Os problemas de abastecimento de gás e petróleo favorecem as tensões ainda muito presente entre países cuja história tem sido marcada por vários conflitos regionais, e às vezes até propensos a problemas sérios de fronteira ainda não resolvidos, apesar de uma arbitragem internacional antigo. Outros países da UNASUL participaram também de várias alianças regionais (ALBA, CAN, OEA, MERCOSUL), o que pode, numa certa medida, atrapalhar os esforços ao longo prazo realizados pela UNASUL. Essas nações se encontram então em uma posição vulnerável contra os dois países hegemônicos (o Brasil e a Argentina) que pretendem se projetar no cenário mundial. Finalmente, não podemos esquecer os grandes desequilíbrios nos orçamentos entre as diferentes Forças Armadas. Esse elemento marca uma falta claro de homogeneidade do Conselho Sul-Americano de Defesa (CSD). Este problema é muito complicado, devido ao fato de que na mesma mesa do Conselho, alguns dos países cuja totalidade do orçamento alocado para gastos militares representa apenas 1\% do orçamento da maior potência da região, o Brasil. 


\section{CONCLUSÃO}

Depois de mostrar a complexidade da Comunidade Sul-Americana para o estabelecimento de uma política comum de integração energética, podemos concluir que as tensões regidas por diferentes atores no continente desde a criação de uma Comunidade de Defesa América do Sul para resolver os problemas relacionados à energia. O processo de integração sul-americano tem apresentado avanços importantes a partir da década de 1990, apesar das pressões geopolíticas e geoeconômicas internas e externas contra a sua efetivação, entretanto também recuos podem ser encontrados principalmente nas freqüentes disputas comerciais entre os dois principais parceiros do bloco: Brasil e Argentina. Tais contradições estão presentes tanto nos acordos bilaterais de alguns países sul-americanos com parceiros de outros blocos econômicos, o que tem enfraquecido o multilateralismo continental, como na tentativa norte-americana de impor o "fast track" como mecanismo de implantação acelerada da Área de Livre Comércio das Américas (ALCA), inviabilizando o cronograma de ajustes necessários para a consolidação do MERCOSUL. O professor Pedro Silva Barros expressou muito bem essa idéia quando explicou que "o quadro político atual da América do Sul expressa a tentativa de reconstruir (ou construir) Estados que foram comprometidos nos anos noventa. As diferenças desses processos de país para país decorre muito menos da formulação teórica dos grupos que chegam ao poder e muito mais das condições e complexidades sociais, institucionais e econômicas de cada lugar. ${ }^{13}$

\section{REFERÊNCIAS BIBLIOGRÁFICAS}

BARRO, Pedro Silva. Chávez e Petróleo: Uma Análise da Nova Política Econômica Venezuelana. IN: Cadernos PROLAM/USP (ano 5 - vol. 2 - 2006)

BUZAN, Barry ; WAEVER, Ole. Regions and Power: The Structure of International Security, Cambridge, Cambridge University Press, 2004

EGLER, Cláudio A.G. Energia e Conflitos territoriais na América do Sul: uma visão geoeconômica. Trabalho apresentado no VII Encontro Nacional da ANPEGE, Niterói, 2007 Disponível em: <http://www.laget.igeo.ufrj.br/egler/pdf/ANPEGE_3.pdf>

LANGUE, Frédérique. Hugo Chavez et le Vénézuela. Une action politique au pays de Bolivar. Editions L'Harmattan, Paris, 2002

PACHECO MIRANDA, Carlos. Importancia Estratégica del gas boliviano. In : Perspectivas Internacionales, $\mathrm{La} \mathrm{Paz}, \mathrm{N}^{\circ} 5$, abril de 2005

13 BARROS, Pedro Silva. Chávez e Petróleo: Uma Análise da Nova Política Econômica Venezuelana. IN: Cadernos PROLAM/USP (ano 5 - vol. 2 - 2006), p. 209 - 237. 
SÁNCHEZ, Alex. The South American Defense Council, UNASUR, the Latin American Military and the Region's Political Process, Council on Hemispheric Affairs. Primeiro de outubro de 2008

ST-PIERRE, Héctor L. Brasil: Política externa y defensa subregional, apresentação para o seminário internacional Límites y desafíos de la agenda de seguridad hemisférica em La Paz em 2008, Observatorio de Democracia y Seguridad \& Woodrow Wilson Center for Scholars

RUDZIT, G. O debate teórico em segurança internacional. Mudanças frente ao terrorismo? Revista Civitas de Ciências Sociais, vol. 5, número 2, jul.-dez. 2005

\section{Documentos}

Declaração de Margarita. Assessoria de Imprensa do Gabinete do Ministério das Relações Exteriores Nota ${ }^{0} 177$ - 18 de abril de 2007. $<$ http://www.itamaraty.gov.br/sala-de-imprensa/notas-aimprensa/2007/04/18/declaracao-de-margarita-construindo-a-integracao>

MINISTERIO DE PLANIFICACIÓN Y DESARROLLO DA REPÚBLICA BOLIVARIANA DA VENEZUELA. Dados sobre o setor do petróleo disponíveis em < http://www.mpd.gov.ve> 